Supporting Information

\title{
Hydrogenation of Carbon Monoxide into Formaldehyde in Liquid Media
}

Ali Mohammad Bahmanpour, Andrew Hoadley, Samir H. Mushrif, and Akshat Tanksale

Totals - 4 pages, 4 figures.

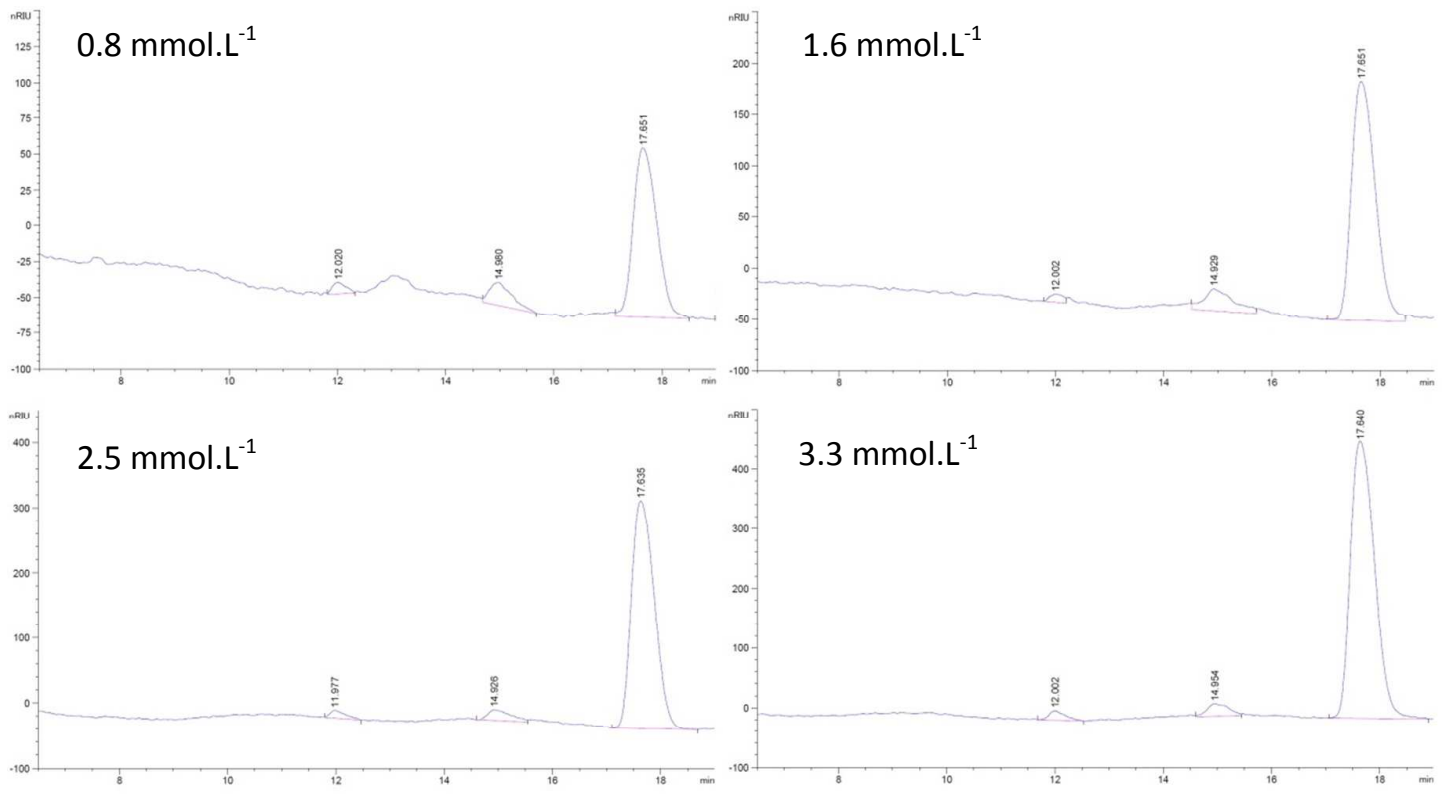

Figure S1: Chromatograms of the standard $\mathrm{HCHO}$ solutions 


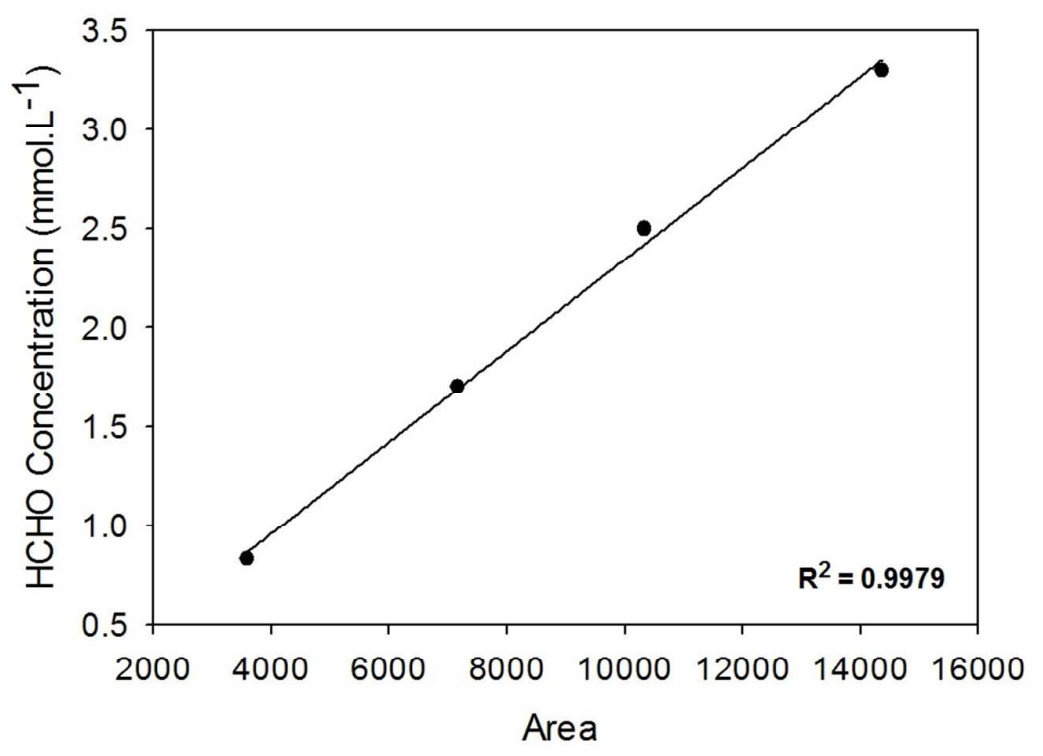

Figure S2: Calibration Curve of HCHO (peak with retention time 17.6 min) on HPLC 


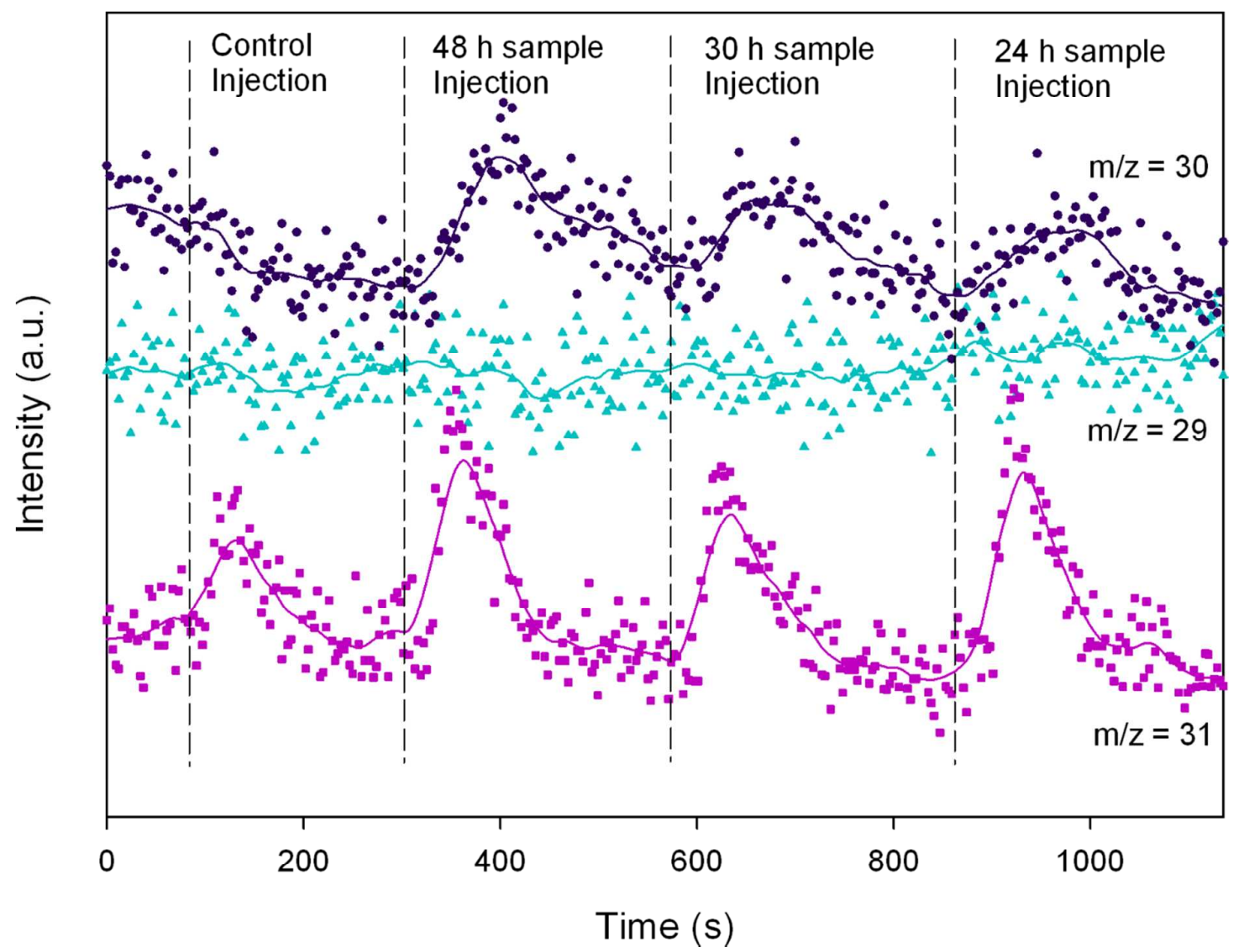

Figure S3: Mass to charge ratio profiles for $\mathrm{HCHO}$ (29), $\mathrm{DCDO}$ (30), and $\mathrm{CH}_{3} \mathrm{OH}$ (31) using $\mathrm{CO}$ and $\mathrm{D}_{2}$ as reactants in $5 \% \mathrm{v} / \mathrm{V} \mathrm{CH}_{3} \mathrm{OH}$ in $\mathrm{H}_{2} \mathrm{O}$ as the solvent. "Control" is defined as the sample at $t=0 \mathrm{~h}$. The bullets are raw data collected every $3 \mathrm{~s}$, whereas the curves are smoothed data using Negative Exponential method which is a local smoothing technique using polynomial regression and weights computed from the Gaussian Density Function. The smoothing of the raw data eliminates the random noise in the raw data and clearly identifies the peaks. 


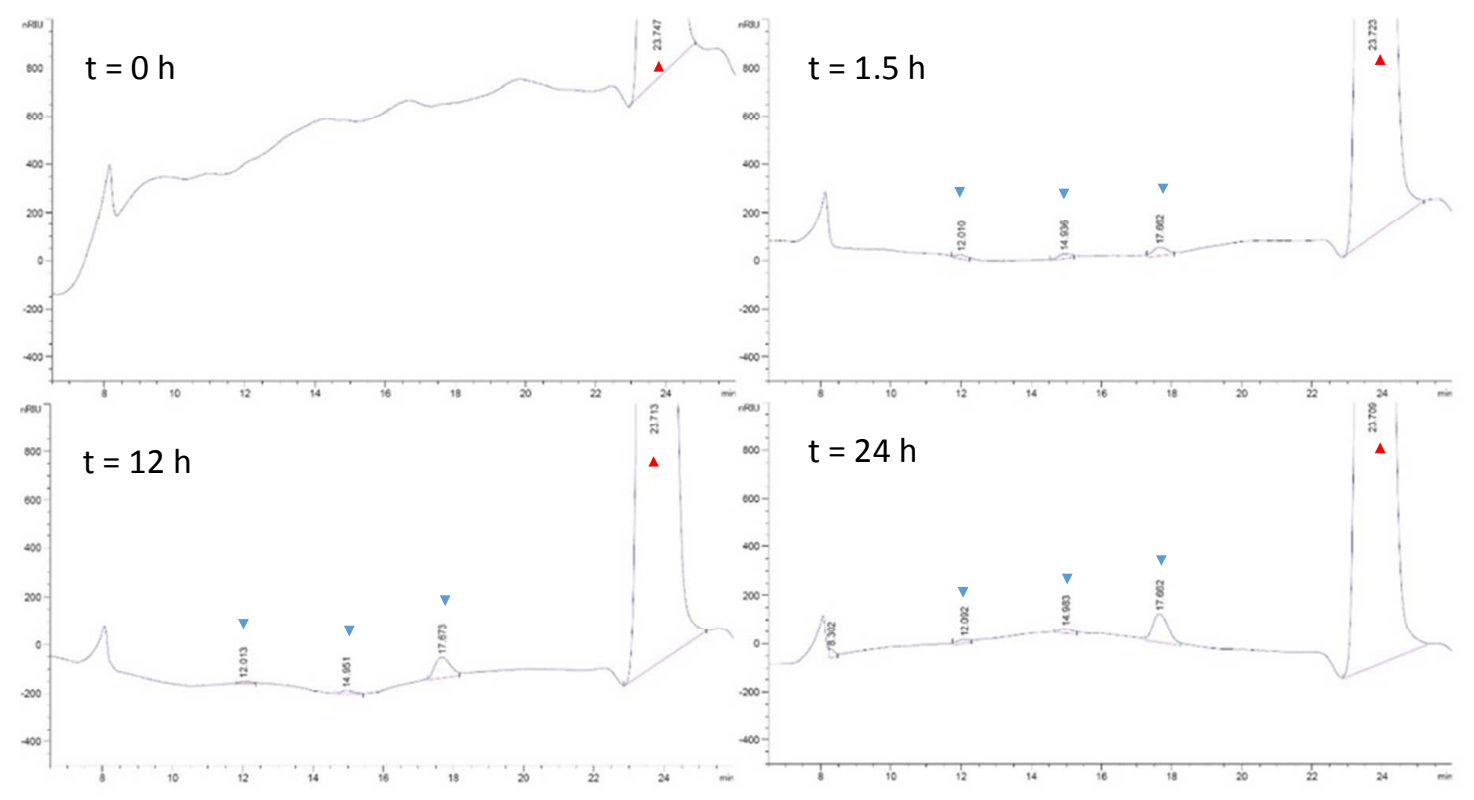

Figure S4: HPLC chromatograms of samples taken at various reaction times. Reaction conditions: $T=353 \mathrm{~K}, P=100$ bar. $\boldsymbol{\nabla}=$ peak associated with standard formalin solution (only peak at 17.6 min was calibrated for $\mathrm{HCHO}$ ); $\mathbf{\Delta}=$ peak associated with methanol 